\title{
EL PROCESO DE LA INSTRUCCIÓN PÚBLICA A 90 AÑOS DE LOS "SIETE ENSAYOS" DE JOSÉ CARLOS MARIÁTEGUI
}

\author{
Eduardo ARROYO LAGUNA \\ Universidad Ricardo Palma \\ earroyo@urp.edu.pe
}

\section{RESUMEN}

La herencia española no ha sido solo un método de instrucción, de educación sino centralmente un régimen económico y social. La educación y la enseñanza deben verse como problemas económico y social. La influencia francesa se insertó, más tarde, en este contexto con la complacencia de quienes miraban en Francia la patria de la libertad jacobina y republicana como de quienes a la vez y al mismo tiempo se inspiraban en el pensamiento y la práctica de la restauración conservadora. La influencia norteamericana se impone al final, aunque con retrocesos, como resultado de un país que iniciaba un embrionario desarrollo capitalista al mismo tiempo que importaba capitales, ideas y técnicos estadounidenses. Se trata de explicar cómo la educación pública peruana ha logrado irrumpir en la sociedad peruana, pero a la vez cómo ésta implica también su fracaso en pleno siglo XXI.

\section{PALABRAS CLAVE}

Instrucción pública, escuela, modernización, Mariátegui, Perú.

\section{THE PUBLIC INSTRUCTION PROCESS 90 YEARS OF THE "SEVEN TESTS" OF JOSÉ CARLOS MARIÁTEGUI}

\section{ABSTRACT}

The Spanish inheritance has not only been a method of instruction, of education but centrally an economic and social regime. Education and teaching must be seen as economic and social problems. The French influence was inserted, later, in this context with the complacency of those who saw in France the homeland of Jacobin and republican freedom as those who at the same time and at the same time were inspired by the thought and practice of conservative restoration. The American influence prevails in the end, although with setbacks, as a result of a country that started an embryonic capitalist development at the same time that it imported American capital, ideas and technicians. The aim is to explain how Peruvian public education has managed to break into Peruvian society, but at the same time how it also implies its failure in the 21 st century.

\section{KEY WORDS}

Public instruction, school, modernization, Mariategui, Peru.

Recibido: 18/03/2019

Aprobado: 30/04/2019 


\title{
INTRODUCCIÓN
}

\begin{abstract}
C ómo tratar el proceso de instrucción pública en un país como el Perú, marcado por la inmoralidad que cruza transversalmente todos sus estratos sociales y todas sus etnias, no solo en la capital sino en todas las regiones estatal frente a las fuerzas sanas, morales de una nación que desea entrar con nuevos bríos a construir su destino y la promesa de la vida republicana?
\end{abstract}

¿No estará indicando la alta corrupción el fracaso de nuestra instrucción pública, de nuestros paradigmas educativos y de los valores que encarna la clásica estructura familiar?

En todo caso, ¿cuál fue la promesa de la vida republicana que Mariátegui evalúa al cumplirse el primer centenario y qué debemos hacer nosotros ahora que ingresamos a conmemorar el bicentenario de nuestra independencia?

¿Bajo qué utopía nace la vida republicana y su proyecto cultural de forjar una instrucción pública que debería incluir a todos detrás de los parámetros de libertad, igualdad y fraternidad?

¿Cómo entender la historia de la instrucción pública al conmemorarse noventa años de los siete ensayos, la obra pilar del análisis de la sociedad peruana hasta hoy en día?

Mariátegui escribe este texto en los estertores de lo que Basadre denomina República aristocrática, gobernada por 14 familias que extiende su poder desde 1890 hasta 1919, con una interrupción durante el oncenio leguiista y la perduración de su poder hasta el año 1968 en que el velascato derrota políticamente a la oligarquía.

A inicios del siglo XX, la generación del 900, novecentistas (José de la Riva Agüero, José Gálvez, Francisco y Ventura García Calderón, Víctor Andrés Belaúnde entre otros), generación también conocida como "Arielista", imaginó un país dirigido por una aristocracia intelectual que solucionaría el conflicto nacional vía el mestizaje con hegemonía de la ideología hispanista; preconizaron el reformismo (Estado fuerte, concertador, democracia corporativa, el equilibrio entrela élite y las masas, sin revolución ni civilismo). Los novecentistas no llegaron en su conjunto a armar un proyecto político que deviniera en un partido político y estuvieron alejados de la arena política concreta. Vieron el Perú desde el balcón similar a Platón que llamaba a gobernar a la aristocracia porque, sostenía, que eran los que mejor pensaban los que debían dirigir al país. Era una concepción de élite alejada de las masas sociales, de iluminados, de gurús.

Los miembros del Centenario (José Carlos Mariátegui, Víctor Raúl Haya de la Torre, Jorge Basadre, Raúl Porras Barrenechea, Emilio Romero y otros) tuvieron otra lectura del país y cuajaron proyectos alternativos de poder, si bien estuvieron lejos de él. Posteriormente en sus años postreros, Haya de la Torre presidió la Asamblea Constituyente de 1978. Mariátegui estuvo lejos del poder y falleció tempranamente. Sus seguidores, la izquierda socialista, han tenido una alta presencia en la forja de la constitución de 1978, en las guerrillas sesenteras o dirigiendo las grandes movilizaciones campesinas que hicieron resonar la voz del Perú profundo en todos los confines del territorio nacional. 


\section{LA IMPRONTA COLONIAL DE LA INSTRUCCIÓN PÚBLICA}

José Carlos Mariátegui nos dice que a cien años de habernos independizado de la monarquía española, la instrucción pública seguía teniendo la impronta colonial.

Ocurrió que la conquista, que no la colonia que coloniza espíritus y transforma territorios, nos trajo conquistadores que se impusieron a sangre y fuego pero no colonizó territorios ni generó industria ni una gran cultura.

La instrucción pública carecía de una visión integral del Perú a construir y seguía la ideología hispana.

Como bien sabemos, la instrucción pública es aquella función que cubre el Estado, encargado de cumplir los mandatos ligados a la educación, la salud, la vivienda, el trabajo para con los ciudadanos. Con la instrucción, además del aporte familiar, se forma al ciudadano desde su niñez, la adolescencia, juventud y adultez. Sean hombres o mujeres, al margen de su raza, etnia, credo, género sexual, el Estado interviene en la formación ciudadana.

Acercándonos al bicentenario, se han separado la instrucción pública y privada primando en la pública el carácter memorístico, muchos profesores de baja calidad académica, colegios y universidades sin servicios, sin laboratorios, con exiguas bibliotecas desactualizadas, un sistema digital medianamente implementado. La instrucción privada se ha convertido en un floreciente negocio.

Hay colegios y universidades digitalizados, en red, que mantienen su superioridad, su dominio en el mercado, sus tarifas altas imposibles de ser cubiertas por alguien perteneciente a los estratos sociales de menores ingresos monetarios.

Mariátegui constata a cien años de la gesta independentista que hay tres influencias en el proceso de la instrucción de la República: la influencia o mejor dicho herencia española, la influencia francesa y la norteamericana. Sostiene que es solo la española la que logra tener un dominio completo. La inclusión de educadores franceses, belgas, holandeses, alemanes, suizos, italianos, ingleses es episódica y no llega a convertirse en una nueva orientación de nuestra política educacional (Mariátegui José Carlos, 1973: 105).

No diferencia Mariátegui lo que es instrucción de lo que es educación, si bien se entiende el tema de referencia y qué significa cuando se refiere a la política educacional a nivel nacional, para todas las clases y etnias.

Lo real es que heredamos el sistema educativo de España, un país europeo rezagado en el progreso capitalista. En su momento, no se había podido emancipar del medioevo faltándole su revolución liberal y burguesa. En cambio, el capitalismoindustrialismo y maquinismo- había alcanzado todo su desarrollo en los pueblos anglosajones-liberales y protestantes.

Los españoles fueron más conquistadores que colonizadores. Carecieron del alma del pioneer, el colono que arriesga. La revolución española se cumplió en las colonias y no en la metrópoli (Mariátegui, 1973: 110). 
Nos dice Mariátegui que en nuestra instrucción pública hay una serie de elementos extranjeros refundidos y combinados. Nuestro pueblo no ha asimilado bien las ideas y a gente de otras latitudes. Por lo menos en la década del 20, convivían sin fusionarse aún, sin entenderse las visiones de los indígenas y de los conquistadores.

Mal hicieron los europeos en maltratar a nuestras culturas ancestrales y discriminarlas creando un Perú de españoles y uno de indios. Nunca pudo haber un mestizaje razonable sino imperó la razón de la fuerza bruta. Nosotros mismos somos mestizos producto de la violencia sobre las mujeres nativas de parte de los invasores europeos.

No se consideraron las costumbres, los valores, el idioma, los dioses de las culturas nativas como iguales y se nos quitó territorio, soberanía, cultura. Lo importante es que "El sentimiento y el interés de las cuatro quintas partes de la población no juegan casi ningún rol en la formación de la nacionalidad y de sus instituciones" (Mariátegui, 1973:106).

Al no haberse nunca considerado las diversas culturas, incluyendo las amazónicas, podemos hablar de un país multicultural, en contraposición con la educación pública limeña, centralista, sin carácter nacional que alimenta aún más el espíritu colonial y colonizador.

Sostiene Mariátegui, al evaluar el centenario de la independencia, que todo nuestro proceso de instrucción y educación carece de un espíritu nacional predominando un carácter colonizador y colonial. Priman los valores del virreinato sobre los de la libertad, igualdad y fraternidad, sobre la promesa de la vida republicana, hija supuesta de procesos independentistas como el norteamericano (1776), inglés (1760) y el de Francia (1789). No sólo eso, sino que acercándonos a nuestro bicentenario, hay quienes aún no entienden que nuestra gesta independentista no empieza con la lucha criolla de 1821 y 1824 sino que encuentra en Túpac Amaru su antecesor sindicando al hombre de Tungasuca solo como un luchador por disminuir los impuestos reales sobre los hombros de los indios y no como el primero en rebelarse contra el régimen colonial en su conjunto, a la vez que Tupac Katary asediaba La Paz.

Por tanto, la promesa de la vida republicana de formar una patria de ciudadanos, de seres iguales, libres y fraternos, no se constata en el centenario de nuestra independencia criolla y hoy, como diría Sinesio López, habría más ciudadanía en la costa, leve en el mundo andino y casi nula en la amazonía, región esta última siempre alejada del conocimiento de la república centralista, que no dejó de lado ese centralismo de génesis virreinal (Sinecio López, 1996).

Careciendo nuestra instrucción y educación de valores propios de un alma nacional, ha primado en los primeros cien años, un sentido aristocrático y un concepto eclesiástico y literario de la enseñanza. Siguió siendo la cultura un asunto de casta, un privilegio de ciertas familias, un privilegio de los poderosos, de las familias adineradas, no un derecho de todos, de los indios que eran amplia mayoría, los que no fueron considerados iguales. Se decían que eran las familias poderosas las que tenían el derecho a la instrucción y educación y no el pueblo, no lo indios. La 
República heredó, pues, los males del virreinato. Como decía Palma, siguieron los mismos actores sociales solo que sin virreyes (Palma, 1964: 1124).

Cuando se habló de igualdad, fue sólo de palabra y no de hecho ya que esa supuesta igualdad solo tenía en la mira a los criollos, a esa patria criolla dominante que es la que resulta de la independencia de 1821. Se valoraba solo al criollo ignorando al indio y al amazónico.

Siempre ha habido dos espacios para educar: uno dentro de la escuela y otro fuera de ella. En la mayoría de los casos, ambas esferas no han estado interrelacionadas constituyendo dos ámbitos separados.

Nacía la República, además, en la miseria lo que le impedía considerar a las grandes mayorías nacionales.

La Independencia no desarrolló un proyecto educativo diferente al que procedía de la colonia española. Al igual que el virreinato, la educación fue un privilegio de pocos, nunca se consideró a los indios, y se impuso sin dudas ni murmuraciones. En todos los casos, la república instala un sistema educativo, valores y una estructura curricular propios de la colonia. La formación es en el idioma español, excluyéndose a quienes no hablaran este idioma, a saber, las grandes mayorías. Hoy mismo, el quechua es una lengua extraña y no reconocida como dominante en nuestro macizo andino. La colonización sigue aún vigente. Hay que entender que el lenguaje no es sólo un idioma sino una forma de entender la realidad.

Al haber subsistido la mentalidad colonial, acabada la efervescencia de la guerra independentista, reapareció el abolengo y principio de privilegio. El mismo hecho del culto a las humanidades y que no se forjaran espíritus laboriosos propios del pioneer, del colono, del que arriesga en el mercado hizo que el nuestro fuera un sistema educativo que formaba sólo abogados, seres de leyes y no hombres de empresa, de industria como el caso sajón, europeo, estadounidense.

Se concibió las universidades y los colegios como fábricas de gentes de letras y leyes, todos alejados de una orientación práctica dirigida a formar empresa, dirigir la nueva industria. Como dice Mariátegui en otro ensayo, las clases medias que dirigieron el proceso independentista, no advinieron en burguesía que lanzara un proyecto nacional que abarcara y comprometiera al conjunto de las clases sociales y etnias de todo el país y se circunscribió a Lima, siguiendo el centralismo de génesis española (Mariátegui, 1973: 46).

No dio cultura a todos los peruanos sino primó el privilegio de casta, de familia centralista, limeña, familia de los poderosos, herencia española no solo psicológica sino económica y social. Por tanto, quedaron todos los remanentes feudales propios del virreinato, en el que más que el negocio, primó el ocio, la holgazanería del que vivió siempre de las rentas de sus tierras, acostumbrado a que otros trabajaran para él y que nunca trabajó en su vida acostumbrado a vivir en la corte. El concepto aristocrático y literario de la educación no cambió quedándonos en el feudalismo.

Así asombrosamente Mariátegui, quien era un pragmático en muchas de sus apreciaciones y preconizaba una real revolución democrático burguesa que 
democratizara en su conjunto al país y lo iniciara en el capitalismo en tránsito al socialismo, sencillamente ve que en los inicios de la república y aún en los años 20 del siglo XX, más valor tenía para las clases dominantes un balcón colonial, el ánimo por las calesas y carruajes coloniales que un building norteamericano (Mariátegui, 1970: 20).

\section{EL APORTE DE MANUEL VICENTE VILLARÁN}

Es hacia 1900 que hace su aparición en la escena pública, el dr. Manuel Vicente Villarán quien, en relación con el proceso de la instrucción pública, discrepa con el carácter aristocratizante hispanista de nuestras políticas educativas y representa, según Mariátegui, el espíritu demoburgués que cuestiona que el Perú se haya convertido unilateralmente en un cenáculo literario y solo emporio de las leyes y de las humanidades, sede de funcionarios y de la burocracia heredando de España el ocio y no el espíritu del negocio, del trabajo.

Para Mariátegui “......Somos un pueblo donde ha entrado la manía de las naciones viejas y decadentes, la enfermedad de hablar y de escribir y no de obrar, de "agitar palabras y no cosas", dolencia lamentable que constituye un signo de laxitud y la flaqueza. Casi todos miramos con horror las profesiones activas que exigen voluntad enérgica y espíritu de lucha, porque no queremos combatir, sufrir, arriesgar y abrirnos paso por nosotros mismos hacia el bienestar y la independencia..... Hasta las manufacturas y el comercio, con sus riesgos y preocupaciones, nos atemorizan, y en cambio contemplamos engrosar año por año...los empleos públicos y las profesiones literarias. En ello somos estimulados, empujados por la sociedad entera. Todas las preferencias de los padres de familia son para los abogados, los doctores, los oficinistas, los literatos y los maestros....y si el mal no es corregido pronto, el Perú va a ser como la China, la tierra prometida de los funcionarios y de los letrados" ( Mariátegui, 1973: 108).

Para Villarán, "La América, no era colonia de trabajo y poblamiento sino de explotación...el indio siervo produjo al rico ocioso y dilapidador......no había trabajador que no fuera siervo....y se llegó a pensar que trabajar era malo y deshonroso...Por raza y nacimiento, el desdén al trabajo, el amor a la adquisición del dinero sin esfuerzo propio, la afición a la ociosidad agradable, el gusto a las fiestas y la tendencia al derroche..." (Villarán, 1919: 27).

\section{LA SEPARACIÓN ENTRE LA EDUCACIÓN Y LAS NECESIDADES MATERIALES}

El proyecto educativo eurocéntrico o mejor dicho de España, su currícula, el modelo de la Universidad de Salamanca se instala aquí basado en las necesidades de Europa y no del Perú. Por ello, el proceso educativo nacional está desarticulado de nuestras propias necesidades. Lo que se dicta está desgajado de la realidad peruana. 
Las carreras profesionales, sus demandas dependen de una lógica comercial y no están articuladas a las necesidades nacionales.

No hay universidades especializadas ligadas a la transformación de los recursos naturales, el conocimiento que provea de valor agregado a la materia prima y que incremente su costo, pudiendo beneficiar ese dinero, a la población pobre en lo más importante que es educarse para salir de la ancestral pobreza.

Podemos decir hoy que en los últimos años, la explotación de los recursos naturales ha mejorado los ingresos de las familias pero la educación no ha mejorado. Podrán tener las familias una camioneta $4 \times 4$ pero siguen siendo los bárbaros de siempre.

Sin embargo, los países con mayor desarrollo, no consideran los recursos naturales sino los métodos y los maestros. Pero son esos países los que nos venden nuestros recursos naturales con valor agregado y viven mejor que nosotros porque invierten en educación y desarrollan una autoestima en las propias capacidades.

\section{LA TENDENCIA ALTRABAJO EN EL MUNDO ANDINO}

Contrasta lo dicho con la tendencia al trabajo que mostrara nuestro mundo andino de pasado inca, en el que había obligación de trabajo para sacar adelante un imperio agrario en el que solo una cuarta parte de las tierras servía para el cultivo y no había mucha agua. Tremendo esfuerzo de nuestros antepasados sobreponiéndose al carácter agreste de la naturaleza y la escasez de recursos. Primó entonces el trabajo como fuente de riqueza y de transformación de la naturaleza.

Primó la planificación, el conocimiento de la naturaleza, la estima de la misma, el estudio del clima y cuidado de la tierra, "no la sobreexplotación de los recursos", concepto colonial y dañino.

Siendo la modernidad una ideología del cambio social y del progreso, nuestro mundo andino hoy estaría más bien en esa línea de pensamiento, a diferencia del clásico criollismo cortesano y no precisamente amigo del trabajo como creador de la riqueza de las naciones. España estaba plagada de prejuicios nobiliarios y sus aficiones burocráticas la alejaban de los campos y de las industrias por creer que era trabajo de esclavos y siervos villanos.

Nada más alejado del peruano que el ocio. La república heredó ese espíritu remolón no emprendedor y lejos de incorporar la capacidad del trabajo andino, prefirió el pasado medioeval hispano.

\section{LA ÉTICA PROTESTANTE Y EL ESPÍRITU DEL CAPITALISMO}

En cambio, los Estados Unidos sí son obra del pioneer, tanto judío como puritano protestante, como diría Max Weber. El espíritu protestante, con gran capacidad y voluntad de trabajo como únicas palancas de desarrollo orientados además hacia fines utilitarios y prácticos, no hacia las leyes y humanidades, genera personas 
dedicadas al trabajo, al ahorro, no dilapidadores como los españoles y nuestra primera burguesía peruana enriquecida con el guano (Weber Max, 1985: 209).

No es que Mariátegui no fuera un poeta, un hombre de pensamiento pero entendía lo que decía.

La república añadió a los vicios españoles los defectos de la influencia francesa que acentuó el concepto literario y retórico de la enseñanza. Condorcet reclamaba igualdad de condiciones para todos los ciudadanos, hombres y mujeres, todas las posibilidades de instrucción, la gratuidad de todos los grados, la triple cultura de las facultades físicas, intelectuales y morales. Pero Napoleón, necesitado de dar instrucción secundaria a sus funcionarios y sus oficiales militares le dioa la universidad, llamada napoleónica precisamente, esa orientación profesionalista que es la que ahora con las connotaciones, acentos e influencias propias del modelo global neoliberal, se desvive tras ramas como telemática, informática, telecomunicaciones, ingeniería de sistemas, mecatrónica. Se han ido al otro extremo y convertido a sus profesionales en doctos tecnificados en su especialidad sin la menor pizca de inteligencia sobre los grandes temas de la humanidad. En suma, se trata de una educación técnica que poco ayuda a pensar si bien está adornada con la tecnología de punta. Es educación que sirve a la lógica del mercado deshumanizando al actor social, al educando.

\section{LA VICTIMIZACIÓN DE LOS PERUANOS}

El otro problema que arrastra la República de 1821 es que no sale de su espíritu de víctima por enfatizar que son los españoles los causantes de todos nuestros males, tras doscientos años de independencia. La cultura de victimización inmoviliza al individuo al cambio, lo manipula a su antojo.

Mientras no abandonemos mentalmente ese pasado y asumamos nuestra responsabilidad hacia el presente y el futuro, no podremos cambiar nuestro destino como país. Siempre la culpa la tendrán los otros, con lo que se habría cumplido la profecía de que los otros tienen la culpa y yo no puedo hacer nada al respecto.

Los sobrevivientes de un holocausto, del genocidio andino, se salvan porque a pesar de su extrema situación piensan en salir de ella y salvarse. Esa idea les permite probar nuevas estrategias para sobrevivir, logrando muchas veces empezar nuevos caminos, lo que no hace el que se autoflagela constantemente considerando que nació con el pie izquierdo tras cinco siglos de la invasión europea.

El concepto de resilencia se aplica para explicar que frente a las situaciones adversas, podemos salir adelante. En este caso, es cuestión de cambiar la noción de víctima y eso lo debe hacer la educación formando en valores proactivos, saliendo adelante a pesar de todas las trabas. Lo hace la educación en la escuela y en la casa con respeto, tolerancia, apoyo moral, una educación sin discriminación ni jerarquías. Desaparece el concepto de educación privada y del Estado para desacreditar a la educación pública como sinónimo de baja calidad. 
Recordemos que los mejores colegios y universidades hasta hace pocos años eran los nacionales. ¿En qué momento cambió este orden de cosas? ¿No fue que la primacía de lo privado terminó discriminando a los pobres, a los indios y andinos?

Tras la Guerra del Pacífico, con un país quebrado casi como al inicio de la República, con Piérola dirigiendo la reorganización de 1895 sobre bases civilistas, recomendó formar una economía capitalista y adaptar gradualmente la instrucción pública a las necesidades de esta economía en desenvolvimiento.

1902: el modelo anglosajón nos influyó. Reformó la segunda enseñanza pero eso a la vez constituyó su limitación al perder perspectiva de integrar todas las áreas de la enseñanza pública. El régimen pierolista no supo ni pudo dar una dirección segura a su política educacional.

\section{LOS APORTES DE LA REFORMA DE 1920}

Villarán aparece en 1900 como quien de modo más coherente preconiza una reforma educativa acorde con el embrionario desarrollo capitalista del país. Su discurso sobre las profesiones liberales combate el concepto aristocrático, literario de la enseñanza transmitido por la república como herencia del virreinato. Sostiene la necesidad de educar a seres humanos útiles y creadores de riqueza. Es más hijo de lo norteamericano, de su positivismo, de su liberalismo.

La reforma de 1920 está dirigida con los planteamientos del doctor Villarán y acompañada por un embrionario desarrollo capitalista del país. Ello significaba políticamente el eclipse de la oligarquía representativa de la casta feudal incapaz en devenir en clase capitalista pero en la medida en que sobreviviera un régimen feudal en la mayor parte del país, saboteaba las posibilidades de una educación nacional que produjera hombres empresarios, industriosos, enérgicos. Al feudalismo le bastaba el indio para asegurar sus ganancias en el campo. El planteamiento norteamericano de Villarán atentaba contra su propia esencia. De hecho, era imposible democratizar la enseñanza de un país si ésta no iba aparejada a la democratización de su economía y de su superestructura política. Requería, además, que cualquier reforma estuviera encabezada por los propios peruanos y no por gente importada de otras latitudes, los que, en todo caso, solo podrían actuar como asesores o colaboradores. Todo lo dicho, llevó al traste a esta reforma. El plan de estudios para la Universidad Nacional Mayor de San Marcos no llegó a ser aplicado; quedaron inconexas varias leyes y reglamentos de enseñanza primaria y secundaria. La Universidad de Escuelas Técnicas fracasó a las primeras tentativas de organización no llegándose a fundar las Escuelas Superiores de Agricultura, Ciencias Pedagógicas, Artes Industriales y Comercio.

Mariátegui, añade como crítica de fondo, el que el proyecto reformista de Villarán mantuviera en la enseñanza, todos los privilegios tanto de clase social como de fortuna. El mundo indígena quedó fuera de estas propuestas y sin ninguna consideración. Conservó la escuela primaria privada y no asignó el sistema de becas, como era de suponer, a los mejores, por estricto orden meritocrático. 
Lo real es que la educación ha sido el privilegio del hombre blanco y no del hombre andino, siempre discriminado.

\section{EL GRITO DE CÓRDOBA}

Coinciden con la virtual aparición de un embrionario capitalismo tanto la reforma de Villarán como la reforma estudiantil argentina de Córdoba, la que se expande por todo el continente entre las vanguardias estudiantiles de la región.

Villarán había representado el pragmatismo positivista norteamericano mientras que Deustua y Víctor Andrés Belaunde quedaban aferrados a la colonia. Deustua representa el extrañanamiento colonial de nuestra educación pública envuelta en un ropaje idealista metafísico.

Es en esos años 1919-1920 que el grito de Córdoba retumba entre el estudiantado contagiando su elan revolucionario. Son dos grandes puntos que claman los jóvenes contra los malos profesores, si bien tardíamente se comprenderá que el burocratismo en el que reposa la instrucción pública no es más que la forma del carácter literario y aristocrático de la instrucción pública, rezagos de la colonia virreinal.

Plantean centralmente dos medidas: la cátedra libre y la asistencia libre así como el cogobierno debiendo participar los estudiantes en el consejo universitario y los órganos de gobierno. Incluye además la revisión de los métodos de enseñanza y del contenido de los estudios; extensión universitaria entendida como la ligazón de la universidad con los movimientos sociales, el pueblo y la sociedad; las universidades populares, uniendo la cátedra a los movimientos populares.

Una reacción conservadora solidaria con los profesores incompetentes tachados por los estudiantes no se hizo esperar expulsando 26 estudiantes en Trujillo, reprimiendo a los estudiantes de la Universidad Nacional Mayor de San marcos quedando sólo como vanguardia la élite profesoral y estudiantil de la Universidad del Cusco.

\section{¿CUÁLES SON LOS SALDOS DE LA INSTRUCCIÓN PÚBLICA EN EL CENTENARIO?}

Resumiendo (Mariátegui José Carlos, 1973: 160):

1. El problema del analfabetismo indígena está casi intacto. Alfabetizar no es lo mismo que educar. En el centenario, la escuela elemental no había redimido moral y socialmente al indio, debiendo pasar esta redención necesariamente por abolir la servidumbre.

2. Hoy en el bicentenario no creo que haya habido mejoras sustantivas, a lo que se añade el racismo del mundo criollo así como la hegemonía de la imagen digital, de los audios como del hiperconsumismo.

Sin embargo, ha cambiado significativamente el rostro social del Perú ya que si en los años 20 del siglo pasado, el grueso de la población del país radicaba en el 
macizo andino, centralmente en el sureste andino (la llamada "mancha india"), es a partir de la década del 50 que se observa una altísima migración del ande hacia la faja costera y centralmente hacia la capital. Lima pasa hacia fines de 1950 de tener 500,000 habitantes a tener 1'500,000 habitantes.

3. El Estado no lleva la instrucción a todo el territorio, caso parecido al bicentenario con grandes bolsones de población infantil y adolescente estudiando en precarias condiciones, sin techo y con un profesor, verdadero héroe que cruza ríos a nado y llega a las aulas a grandes distancias. Los poblados suelen estar alejados de las escuelas debiendo caminar los estudiantes grandes distancias a pie.

4. Nada de digitalizaciones ni siquiera electrificación y agua masiva en los poblados de nuestra serranía y amazonía.

5. La misma educación está siendo cambiada por el mundo digital. Predominancia de la imagen, del audio, del video. Hoy no se lee o se lee poco, todo se da por la vía digital. Se sufre con las separatas, ni siquiera lectura de libros. Los jóvenes son "homo videns" como diría Sartori. Es un mundo facilista en que con el movimiento de una tecla tienen todo el conocimiento de la humanidad almacenado en sus I-pods. La misma máquina resuelve problemas matemáticos así como las calculadoras. Ello lleva a que no se piense al tener todo resuelto. La escuela ha fracasado en enseñar a pensar. La máquina resuelve todo. No más trabajo solitario de bibliotecas.

6. Además hay un cholo power. Si tienes plata, no estudias y vas a la universidad con tu camioneta $4 \times 4$ para impresionar a las chicas fáciles y casquivanas. El rey de la papa y el rey de Gamarra no tributan, a diferencia de los empresarios de EEUU y de Europa en donde se pagan los impuestos de ley en cada producto que se consume.

7. ¿Cómo quieren una educación pública de calidad si no se tributa? ¿De dónde saldrá el dinero para instrumentar estas universidades y colegios y conseguir buenos profesores bien pagados, buenas bibliotecas? Lo otro es camino a la corrupción, al copia y pega de monografías.

8. Se sigue con una enseñanza en el idioma castellano y no en quechua o en los dialectos amazónicos. Se carece de los temas propios de la región, debiendo ser la enseñanza en el dialecto regional y dictado por profesores de la localidad.

9. Se carece del número suficiente de maestros.

10. El centenario no ha revalorado la función del amauta y en el bicentenario sigue sin valorarse la tarea del maestro, profesión entendida por la población y por las castas dominantes como las que asumen los desheredados de toda riqueza y aquellos que fracasan en estudiar otras cosas. Sin revalorarse la tarea del amauta no hay futuro en la instrucción pública a diferencia de Dinamarca, Noruega, Cuba, Japón, Corea del Sur con gran revaloración de 
la tarea educativa y del maestro como de la escuela en su conjunto, desde el kindergarden considerada en los países nórdicos como solo propio de los mejores maestros mientras aquí se pone el peso en la enseñanza universitaria con fofas y endebles bases epistemológicas y en la primaria y secundaria.

11. En general, estos países tienen ideas propias acordes con su realidad.

12. Las "Universidades Populares" González Prada, la adhesión de la juventud universitaria al principio de la socialización de la cultura, el ascendiente de un nuevo ideario social educacional sobre los maestros, etc. interrumpen definitivamente el erudito y académico diálogo entre el espíritu demoliberalburgués y el espíritu latifundista y aristocrático.

A los maestros no les está asegurado un sueldo mínimo responsable y digno tanto en el centenario como hoy en el bicentenario. "La carrera de maestros de primera enseñanza es una carrera de miseria" (Mariátegui, 1973: 160). Recordar la gran huelga magisterial en el 2016 y 2017 que tumbó a ministros ante la complicidad del aprofujimorismo como de las alas ultraizquierdistas en el magisterio nacional.

El único gobierno con política integral educativa vinculada al pueblo, al agro, al bosque, a la industria fue el de Velasco Alvarado. Unió la reforma educativa a la reforma industrial, agraria, bancaria, etc. Incluyó al mundo andino, lo alfabetizó y le dio derecho a voto, incluyendo a los hijos naturales. Reivindicó el quechua y al campesinado. Habría que volver a sus bases, premisas de pensamiento y funcionamiento, en un Perú que ya no es el de los tiempos de Mariátegui.

Hoy es un país de unos treinta millones de habitantes y ya el cuadro no es el de una población mayoritaria en el macizo andino sino que se ha producido desde fines de la segunda guerra mundial y años cincuenta una extensa migración sin recurrencia hacia la costa centralmente hacia Lima amestizándose la población y densificándose la población costera y limeña.

\section{SÍNTESIS}

Como dice Mariátegui, la herencia española no ha sido solo un método de instrucción, de educación sino centralmente un régimen económico y social. La educación y la enseñanza deben verse como problemas económico y social. La influencia francesa se insertó, más tarde, en este contexto con la complacencia de quienes miraban en Francia la patria de la libertad jacobina y republicana como de quienes a la vez y al mismo tiempo se inspiraban en el pensamiento y la práctica de la restauración conservadora. La influencia norteamericana se impone al final, aunque con retrocesos, como resultado de un país que iniciaba un embrionario desarrollo capitalista al mismo tiempo que importaba capitales, ideas y técnicos estadounidenses.

Entrará en colisión un inicial capitalismo con el feudalismo que primaba en todo el territorio nacional basado no solo en el sistema de posesión de la tierra sino en 
la consideración del indio como siervo y en la mentalidad medioeval y feudal del indio, cuyo problema central siempre fue el luchar por tierra propia, nudo de las reformas agrarias.

La incursión de corrientes socialistas traerá un nuevo mensaje en los años 20 del siglo XX, no en el bicentenario con una izquierda tradicionalmente fragmentada y sin peso específico en la historia nacional. Hoy se requiere de un balance a profundidad de la izquierda socialista. Tiene una grave responsabilidad en el estado de las cosas.

Un concepto moderno de la escuela coloca en la misma categoría el trabajo manual y el intelectual. La escuela del trabajo es un producto genuino, una concepción fundamental de una civilización creada por el trabajo y para el trabajo. Hay que crear una civilización del trabajo y una civilización de trabajadores (Mariátegui José Carlos, 1973: 158).

En suma, frente al académico demoliberal-burgués enfrentado al espíritu asfixiante latifundista y aristocrático hijo de la colonia virreinal, surge la corriente socialista y una nueva conciencia de clase. ¿Será real? Hoy en el 2018 ¿Qué ha cambiado? ¿Hemos cambiado?

Mucha agua ha corrido bajo el puente y habría que abrir nuevos cauces al balance serio del proceso de nuestra instrucción pública.

\section{BIBLIOGRAFÍA}

López, Sinesio (1996). "Perú: Mapas de una Ciudadanía Inconclusa. La Condición Ciudadana". Lima: Ed. V-nómica.

Mariátegui, José Carlos. (abril de 1973). "7 ensayos de interpretación de la realidad peruana". Lima-Perú: Vigésimasexta y duodécima edición popular, Biblioteca AMAUTA.

- (16 de abril de 1970). "Peruanicemos al Perú". Lima-Perú: Biblioteca AMAUTA.

Palma, Ricardo (1964). "Tradiciones Peruanas Completas". Edición y prólogo de Edith Palma, nieta del autor. España: Ediciones Aguilar S. A., quinta edición.

Villarán, Manuel Vicente (1919). "Las reformas de la instrucción Pública". Discurso pronunciado en la apertura del año universitario de la Universidad Nacional Mayor de San Marcos de 1919. Revista Universitaria.

Weber, Max (1985). "La ética protestante y el espíritu del capitalismo". Argentina: Ediciones Orbis, S.A., distribuido para América Latina por Hyspamérica Ediciones argentina, S.A. 